\title{
VISIONES DEL MUNDO ANIMAL EN LA ESPAÑA MODERNA
}

\author{
ARtUro Morgado GARCíA* \\ Universidad de Cádiz
}

Fecha de recepción: octubre de 2010

Fecha de aceptación: enero de 2011

Aunque en España esta línea de investigación se encuentra poco desarrollada, en los mundos académicos francés y anglosajón la denominada Zoohistoire ${ }^{1}$ o Cultural History of Animals ${ }^{2}$ goza de un amplio predicamento, y nos ha permitido tomar conciencia del hecho de que la percepción del mundo animal por parte del ser humano es, como todo, un producto cultural, y, por consiguiente, algo cambiante y evolutivo. Habida cuenta de esta laguna en el estado actual de nuestros conocimientos, este pequeño trabajo pretende solamente ofrecer algunas fuentes documentales y poner de relieve algunas reflexiones que puedan servir como punto de partida (y jamás de llegada) para futuras investigaciones sobre zoohistoria en el mundo hispánico.

Mencionamos anteriormente que la visión del mundo animal ha experimentado grandes transformaciones a lo largo del tiempo. En este sentido, aunque sea un esquema meramente provisional y susceptible de modificaciones, habría que distinguir una primera fase, que llegaría hasta mediados del Seiscientos, en la que predomina la visión simbólica, según la cual los animales tienden a ser considerados, en última instancia, como un mero espejo de los vicios y virtudes humanos. A la segunda fase la podríamos llamar positivista. Es cierto que es anacrónico emplear este término para la Modernidad, pero no lo es menos que las preocupaciones propias del positivismo cien-

\footnotetext{
* Profesor Titular de Historia Moderna. Universidad de Cádiz. Facultad de Filosofía y Letras de Cádiz

Avda. Gómez Ulla s/n 11003 Cádiz. Tfno. (956) 015575. E-mail: arturo.morgadogarcia@uca.es

1. Es el término que utiliza Robert Delort, pionero de estas cuestiones en la historiografía francesa, en su obra Les animaux ont une histoire (París, 1984).

2. Una síntesis reciente en KALOF, Linda, y RESL, Brigitte (coord.), A cultural history of animals, 6 vols., Oxford, Berg Publishers, 2007, que incluye una amplia bibliografía y es muy válida como punto de partida.
} 
tífico, no consolidado hasta un siglo XIX que hizo de la presunta objetividad del investigador todo un mito $^{3}$, tienen sus antecedentes en nuestra época con la consolidación de los intereses descriptivistas que empiezan a predominar (aunque con precedentes que podemos remontar hasta Aristóteles) a partir del siglo XVII siguiendo las pautas establecidas por lo que se ha dado en llamar el método científico. Y la tercera fase, la afectiva (muy relacionada con su antítesis, la visión utilitaria, que siempre ha estado presente), que no empieza a dar frutos hasta el siglo XIX con las primeras medidas proteccionistas (aunque con antecedentes muy antiguos, siendo Plutarco el ejemplo más destacado), y que se caracterizaría por el intento de establecer un marco de relación más igualitario entre los animales y los seres humanos, a la par que se consolida su papel como iconos del universo infantil. Todas estas visiones, en mayor o menor medida, las vamos a encontrar a lo largo de la Modernidad española 4 .

\section{LA VISIÓN SIMBÓLICA}

Los primeros estudios sistemáticos de zoología descriptiva, como bien es sabido, fueron obra de Aristóteles, si bien estos empeños no tuvieron continuidad en el mundo clásico, de tal modo que sus sucesores, de los que podríamos destacar a Plinio, Claudio Eliano, Solino, y el epílogo que supondría la figura de Isidoro de Sevilla, realizarían un nuevo enfoque, en el que confluirían a la par la moralización del mundo animal, en el que cada especie se podría asimilar a una virtud o un vicio humano, lo cual, a su vez, era el fruto de la tradición fabulística iniciada por Esopo; y el recurso a lo mágico, lo mítico, lo maravilloso y lo fantástico, en el que la India supone la tierra de maravillas por excelencia, lo que ya apreciamos en la obra de Heródoto ${ }^{5}$.

La Edad Media heredaría ambas tendencias, inspirándose sobre todo en la obra del Fisiólogo, supuestamente atribuido a san Epifanio (cuya traducción del griego fuera publicada en la Roma de 1587 por Gonzalo Ponce de León), copiada, ampliada, adulterada y plagiada hasta la saciedad durante este período, y que daría origen a los tan conocidos bestiarios, en los que predominaría igualmente la visión simbólica. El siglo XVI no supondría en absoluto una ruptura con la cosmovisión zoológica heredada del pasado. Lo maravilloso y lo mítico, muy reforzados por la publicación de la obra de Olao Magno ${ }^{6}$, que trasladará el reino de las maravillas de la India a los mares

3. Cfr. Daston, Lorraine, y Galison, Peter, Objectivity, Boston, Zone Books, 2007.

4. Una buena panorámica de las distintas vertientes del estudio de los animales durante esta época, en ENENKEL, K.A.E., y SMITH, Paul J., Early modern zoology: the construction of animals in science, literature and the visual arts, Brill, 2007.

5. WitTKOWER, Rudolf, «Maravillas de Oriente: Estudio sobre la historia de los monstruos», Sobre la arquitectura en la edad del Humanismo. Ensayos y escritos. Barcelona, Editorial Gustavo Gili, 1979, pp. 265311.

6. Olao Magno, Historia de las gentes septentrionales, Madrid, Tecnos, 1989, edición de Daniel Terán Fierro, que utiliza el epítome latino publicado en Amberes en 1562. La primera versión se publicaría en Roma en 1555. 
del Septentrión ${ }^{7}$, seguirán teniendo cabida en la abundante literatura teratológica publicada durante este período, a la par que la vertiente simbólica se vería reforzada por la difusión de la literatura emblemática, visión simbólica de la que participarían, en el caso español, obras como las escritas por Jerónimo Cortés, Libro y tratado de los animales terrestres y volátiles (Valencia, 1613), Andrés Ferrer de Valdecebro, Gobierno general, moral y politico, hallado en las fieras y animales silvestres (Madrid,1658)(en la que se explaya sobre el significado simbólico del león, el elefante, el rinoceronte, el unicornio, el tigre, la onza, el leopardo, la hiena, el lobo, el lince, el oso, el jabalí, el ciervo, el toro, el camello, el caballo, el can y el cinocéfalo) y Gobierno general, moral y político, hallado en las aves...añadido con las aves monstruosas (Madrid, 1683), Francisco Garau, El sabio instruido de la naturaleza en cuarenta máximas políticas y morales (Barcelona, 1702), Francisco Marcuello, Primera parte de la historia natural y moral de las aves (Madrid, 1617), o Ramírez de Carrión, Maravillas de naturaleza (Córdoba, 1629).

La visión simbólica del mundo animal ha sido bastante estudiada en lo que se refiere a la España moderna, y los historiadores del arte son, probablemente, los que nos han ofrecido mayor número de aportaciones a través del tratamiento de la literatura emblemática ${ }^{8}$, en cuyo análisis tendríamos que destacar a José Julio García Arranz, especialmente la obra que en su momento constituyó su tesis doctoral Ornitología emblemática (Universidad de Extremadura, 1996), acompañada de numerosos trabajos posteriores ${ }^{9}$. Esta visión simbólica es la que han abordado también, normalmente, los historiadores de la literatura, a los que debemos algunas aportaciones relativas a la

7. Y que será dado a conocer a los españoles por la obra de Antonio de Torquemada Jardín de flores curiosas (Salamanca, 1570), edición moderna a cargo de Giovanni Allegra. Madrid, Castalia, 1982.

8. Picinello, Francisco, El mundo simbólico. Serpientes y animales venenosos. Los insectos, México, El Colegio de Michoacán, 1999, a destacar los estudios introductorios, RoIG CondominA, V.M., «Los emblemas animalísticos de fray Andrés Ferrer de Valdecebro», Goya, 187-188, 1985, o SOLERA LOPEZ, R., «Estudio iconográfico del jabalí como animal simbólico y emblemático», Emblemata: Revista aragonesa de emblemática, 7 (2001).

9. «La literatura animalística ilustrada en España durante la Edad Moderna: una panorámica», Libros con arte, arte con libros, 2007; «Olao Magno y la difusión de noticias sobre fauna exótica del norte de Europa en el siglo XVI», Encuentro de civilizaciones (1500-1750): informar, narrar, celebrar: actas del tercer Coloquio Internacional sobre relaciones de sucesos, Cagliari, 5-8 de septiembre de 2001, 2003; "Las enciclopedias animalísticas de los siglos XVI y XVII y los emblemas: un ejemplo de simbiosis», Del libro de emblemas a la ciudad simbólica, 2000; «La visión de la Naturaleza en los emblemistas españoles del siglo XVII», Literatura emblemática hispánica: actas del I Simposio Internacional, 1996; "Fauna americana en los emblemas europeos de los siglos XVI y XVII», Cuadernos de arte e iconografia, 11, 1993, «El papagayo y la serpiente: historia natural de una empresa de Diego Saavedra Fajardo», Norba. Arte, 26, 2006. 
fauna, real o fantástica, descrita en la literatura religiosa ${ }^{10}$, o alguna referencia a la obra fabulística de Samaniego ${ }^{11}$.

La hagiografía constituye una plataforma privilegiada para observar el tratamiento simbólico al que son sometidas numerosas especies animales. La funcionalidad del género era muy variada, no sólo porque ofrecía modelos de virtud y de comportamiento ejemplar, sino porque contenía todos los elementos propios de un relato de aventuras, a saber, lo exótico, lo maravilloso, lo fantástico, lo espectacular, y lo truculento, lo que le confería un fuerte carácter escapista ${ }^{12}$. Aunque no en demasiadas ocasiones, los animales también constituyen un elemento del relato hagiográfico, bien sea porque el demonio toma forma de tales, bien porque no se atreven a dañar al santo en cuestión, bien porque el protagonista libera a la comunidad de alguna plaga o de algún animal especialmente dañino, o bien porque la bondad del santo se refleja también en el cuidado y la piedad que manifiesta hacia algún animal concreto ${ }^{13}$.

La referencia a los numerosos santos ascetas que pasaron su vida en el desierto, purificando sus culpas mediante una vida llena de compunción y de penitencia, constituye uno de los tópicos más recurrentes del género. Uno de estos santos sería San Macario Alejandrino, discípulo nada menos que de San Antonio, y que, al igual que su maestro, optó por retirarse a la lejana Tebaida, en el alto Egipto, no andándose con contemplaciones a la hora de mantener su perfección espiritual ${ }^{14}$. Pero el relato hagiográfico destaca por la aparición de un animal del cual apenas existen referencias en el género, a saber, la hiena. Durante mucho tiempo no se tuvo muy clara la naturaleza de esta criatura, y era bastante frecuente confundirla con el lobo ${ }^{15}$, estando muy extendida la creencia de que era hermafrodita ${ }^{16}, \mathrm{y}$, aunque Ferrer de Valdecebro lo considera algo sin fundamento, la pone como ejemplo de la discordia, por simbolizar dos naturalezas opuestas y enfrentadas. La opinión sobre este animal no era, pues, muy halagueña,

10. Cuevas Garcia, C.1, «El bestiario simbólico en el Cántico Espiritual de san Juan de la Cruz», Simposio sobre san Juan de la Cruz (1986). GOMEZ MORENo, A., Claves hagiográficas de la literatura española (del Cantar de mio Cid a Cervantes), Iberoamericana/Vervuet, 2008. HernANDEZ MERCEDES, M.P., «El bestiario alegórico en el Dilucidario del verdadero espíritu de Jerónimo Gracián de la Madre de Dios», Estado actual de los estudios sobre el Siglo de Oro, vol. 1, Salamanca, Universidad, 1993, pp. 473-479.

11. Palacios Fernandez, E., «Las fábulas de Félix María de Samaniego: fabulario, bestiario, fisiognomía y lección moral», Revista de literatura, 119, 1998.

12. Alvarez SANTALO, León Carlos, «La oferta de pautas de conducta y la cimentación de valores en el libro devocional del Barroco: un ensayo metodológico», Archivo Hispalense, 220, 1989.

13. Para la hagiografía medieval, es clave GuILBERT, L., «L' animal dans la Legende doree», Legenda aurea: sept siecles de diffusion, Montreal, 1986.

14. Ribadeneyra, Pedro de, Flos sanctorum, Barcelona, Imprenta de los consortes Sierra, Oliver y Martí, 1790, tomo I, p. 92.

15. FERRER DE VALDECEBRO, Andrés, Gobierno general moral y politico hallado en las fieras y animales silvestres, Madrid, Antonio de Zafra, 1680, p. 176.

16. Sobre la visión hermafrodita de la hiena, Boswell, William, Cristianismo, tolerancia social y homosexualidad, Barcelona, Muchnik, 1998. Agradecemos al profesor Francisco Vázquez García el habernos proporcionado esta referencia. 
y ello contrasta con el benéfico papel que en cierta ocasión jugaría en la vida de San Macario, en agradecimiento a un milagro realizado por el santo (lo que nos prueba que la providencia divina vela por todas las criaturas, aún las más despreciables) ${ }^{17}$.

Dentro de la simbología animal, el ciervo siempre ha gozado de un carácter privilegiado, dado su condición de criatura fuertemente ligada a la figura de Jesucristo. Ya Plinio describe a la serpiente como enemigo del ciervo, lo que permitirá al Fisiólogo griego establecer un paralelismo con las figuras del Demonio y de Cristo. Asimismo, la capacidad de renovar su cornamenta es comparada con la regeneración espiritual de los cristianos tras la recepción de los sacramentos. No es por ello de extrañar que la caza del ciervo sea, desde la Edad Media, la caza más noble. Ni tampoco el destacado papel que en muchas ocasiones juegan los ciervos en los relatos hagiográficos, al menos si seguimos, nuevamente, al Flos sanctorum de Ribadeneyra. Algunas veces el significado cristológico es muy evidente, como le aconteciera a San Eustaquio mártir ${ }^{18}$. Otras veces, el ciervo aparece como un claro bienhechor del santo, tal como le sucediera a Santa Ofita virgen y mártir ${ }^{19}$. Lo más habitual, sin embargo, será que el santo ayude a un ciervo acosado por sus enemigos, como hicieran San Fructuoso ${ }^{20}$ o San Gil Abad ${ }^{21}$. Y un ciervo perseguido por los cazadores encontraría refugio bajo el manto de San Humberto ${ }^{22}$.

Una de las imágenes que más ha pesado en la visión tópica de los primeros siglos del cristianismo es la de los pacíficos e inocentes seguidores de Jesús arrojados a las bestias feroces por mandato de algún cruento y corrupto emperador. Sin discutir ahora acerca del impacto real de las persecuciones, tema sobre el cual se ha exagerado muchísimo, aunque haya servido para poblar el santoral de numerosos mártires y para que los hagiógrafos alimentaran el morbo de sus lectores aludiendo a los crueles tormentos padecidos por aquéllos, lo cierto es que no siempre las fieras acabaron con la vida de los santos, antes al contrario, en muchas ocasiones, tal como nos muestra Ribadeneyra, su bondad y su fidelidad a Cristo triunfaron sobre la crueldad de los leones, siendo muy sintomático el caso de Santa Martina virgen ${ }^{23}$. Pero los leones no solamente respetaron la vida de los mártires. También encontramos a santos ascetas retirados al desierto para llevar una vida de penitencia, que en más de una ocasión se cruzan con un león que, milagrosamente, no arremete contra ellos, como le sucedería a San Pablo, primer ermitaño y confesor ${ }^{24}$. Y un león cavaría la tumba de Santa María Egipcíaca ${ }^{25}$.

17. Ribadeneyra, Pedro de, op. cit., tomo I, p. 93.

18. RiBAdeneyra, Pedro de, op. cit., tomo III, p. 76.

19. RIBADENEYRA, Pedro de, op. cit., tomo III, p. 188.

20. RibAdENEYRA, Pedro de, op. cit., tomo I, p. 609.

21. RiBADENEYRA, Pedro de, op. cit., tomo III, p. 1.

22. RiBADENEYRA, Pedro de, op. cit., tomo III, p. 561.

23. RibAdeneyra, Pedro de, op. cit., tomo I, p. 98.

24. RiBAdeneyra, Pedro de, op. cit., tomo I, pp. 154-155.

25. RiBAdeneyra, Pedro de, op. cit., tomo I, p. 561. 
El dominio ejercido por los santos (con la ayuda divina, naturalmente) sobre los animales resulta especialmente sintomático en el caso de las serpientes. La visión cultural de éstas ha sido muy cambiante a lo largo del tiempo: veneradas en el mundo clásico (eran identificadas con Esculapio), el cristianismo, como consecuencia de la herencia judía, aportó una imagen totalmente negativa. De hecho, las serpientes pertenecen al género más vil de animales que pueda imaginarse, los reptilia, el lugar más bajo posible en la jerarquía habitacional que durante mucho tiempo se utilizará para clasificar las diferentes especies. Por tales motivos no ha de resultar extraño que, en más de una ocasión, nos encontremos con santos controlando a tan inmundas criaturas, aunque ello no tiene porqué denotar el dominio sobre las huestes demoníacas, sino, simplemente, el poder sobre aquellas zonas salvajes que normalmente permanecen al margen de la presencia humana, así como sobre las bestias que las habitan, siendo éste el caso de San Hilario obispo ${ }^{26}$. No olvidemos el conocido episodio de San Pablo ambientado en la isla de Malta, cuando una víbora se le subió al brazo sin hacerle daño alguno y él la arrojó al fuego. Ni la proeza de san Patricio de Irlanda, que erradicaría las serpientes de dicha isla ${ }^{27}$.

Un segundo género literario a través del cual podemos apreciar la omnipresencia de la tradición simbólica es la fabulística, que seguirá plenamente operativa en la Modernidad, como atestiguan las numerosas reediciones de las obras de Esopo y Fedro, conociendo mucho éxito las realizadas por Heinrich Steinhowel (1412-1482), cuya obra fue traducida al español en una edición publicada en Sevilla en 1521 como Libro del sabio [et] clarissimo fabulador Ysopu hystoriado [et] anotado. El bestiario aparecido en la versión hispalense se caracteriza por ser totalmente familiar para los lectores, ya que la presencia de animales exóticos brilla prácticamente por su ausencia, exceptuando alguna aparición esporádica del tigre o del camello. Tampoco hay concesiones a animales fabulosos o míticos, si hacemos excepción del dragón o los monstruos, ambos figurantes en una ocasión. Serán los mamíferos, con gran diferencia, los animales más representados: podemos comparar las cuatro fábulas en las que aparecen el águila o el gallo, las aves con una presencia más recurrente, las cinco de la rana, o las tres de la hormiga (el insecto más representado), frente a las ocho del asno, las trece del perro, las catorce del león, las diez y nueve de la raposa, o las veintre y trés del lobo. Habría que profundizar en esta cuestión, pero es probable que, dado el talante fuertemente moralizante con la que es presentado el mundo animal, sean los mamíferos las criaturas más fácilmente asimilables a virtudes y vicios, y, de hecho, los animales más frecuentes pueden ser inmediatamente situados en esta escala de valores: la estupidez del asno, la lealtad del perro, la clemencia y la fiereza del león, la astucia de la raposa, y la crueldad (y la estulticia) del lobo. Por citar un ejemplo muy conocido, la famosa recopilación antropomórfica francesa, el Roman de Renart, atribuye dichos caracteres al león, el lobo, y el zorro.

26. Ribadeneyra, Pedro de, op. cit., tomo I, p. 146).

27. Ribadeneyra, Pedro de, op. cit., tomo I, p. 504. 
No obstante, no hay que destacar tan sólo los rasgos morales atribuibles a cada especie animal, sino también estudiar las relaciones y las oposiciones establecidas entre ellos, para lo cual sería útil estudiar los que figuran en los primeros puestos. Destaca ante todo la asociación establecida entre el lobo con la oveja (o, lo que es lo mismo, el cordero y el carnero), que aparece en media docena de ocasiones, tantas como la que encontramos entre el lobo y la raposa, a las que les seguirán las parejas perro/lobo (cuatro fábulas), hombre/león (cuatro), lobo/cabra (tres), lobo/asno (tres), perro/oveja (tres), león/cabra (tres), y león/asno (tres). Como de lo que se trata es de contraponer virtudes y vicios, parece que el fabulista quiere poner de relieve básicamente la dicotomía entre la astucia y la estupidez, especialmente reforzada cuando la primera está presente en un animal débil, y la segunda en un ser aparentemente cruel y voraz, de ahí que la pareja estrella sea la formada por el lobo y la raposa...tal cual en el Roman de Renart. El lenguaje de la fábula, como vemos, está lleno de tópicos, pero son precisamente esos tópicos los que han condicionado la visión del mundo animal durante siglos.

En el siglo XVIII la fábula sigue estando muy presente. Por supuesto, a través de sus cultivadores más conocidos, Tomás Ruiz de Iriarte (Fábulas, Madrid, 1782), y Félix María de Samaniego (Fábulas, Valencia, 1781-1784). Pero también a través de las traducciones de las obras de Esopo y Fedro (Juan de Lama, Fábulas y vida de Esopo, Madrid, 1739; Santos Díez González, Fábulas de Fedro, Madrid, 1781; Alfonso Gómez Zapata, Fábulas de Fedro, Madrid, 1789), los numerosos ejemplos que encontramos en la prensa dieciochesca, u otras recopilaciones, menos conocidas, pero que no dejan de tener su interés: así, Bernardo María de la Calzada con sus Fábulas morales escogidas de Juan de la Fontaine en verso castellano (Madrid, 1787), o José Agustín Ibáñez de la Rentería en Fábulas en verso castellano (Madrid, 1789-1792).

La visión simbólica del mundo animal es inseparable, obviamente, de toda una concepción epistemológica. En opinión de Ashworth ${ }^{28}$, que la denomina visión emblemática de la naturaleza, los animales constituyen un elemento más de un intrincado lenguaje de metáforas, símbolos y emblemas, representando un factor primordial en la historia natural del Renacimiento, y confluyendo varias tradiciones, a saber, la jeroglífica de Horapolo, la anticuaria (que se basaba en las monedas y medallas de la Antigüedad), la esópica, la mitológica de Ovidio, Natale Conti o Vincenzo Cartari, la adágica de Erasmo y la emblemática de Alciato (por cierto, todas estas fuentes son mencionadas en una obra muy interesante para comprobar la presencia de esta visión simbólica de la naturaleza en España, a saber, el Tesoro de la lengua castellana de Covarrubias). Como muy bien dijera Foucault, los signos formaban parte de las cosas, y no se habían convertido en meros modos de representación: al fin y al cabo, Aldrovandi

28. ASHWORTH, William B. Jr., «Natural History and the Emblematic World», LINDBERG, D.C., y WESTMAN, R. S., Reappraisals of the Scientific Revolution, Cambridge U.P., 1990. Reeditado en HELLYER, M., The scientific revolution: the essential readings, Blackwell, 2003. 
no era ni mejor ni peor observador que Buffon, y parece saber muchas más cosas que Jan Jonston, lo único que ocurre es que la perspectiva epistemológica es diferente ${ }^{29}$.

\section{LA VISIÓN POSITIVISTA}

A partir del siglo XVI comienzan a publicarse algunas grandes recopilaciones zoológicas, pudiendo destacarse al respecto, aunque el espíritu que las anime sea en ocasiones muy distinto, las obras de Conrad Gessner ${ }^{30}$, Pierre Belon ${ }^{31}$, Guillaume Rondelet $^{32}$, Hipólito Salviani ${ }^{33}$, Ulises Aldrovandi ${ }^{34}$, y, ya en el siglo XVII, las de Edward Topsell ${ }^{35}$, y Jan (o Johannes) Jonston ${ }^{36}$. Al mismo tiempo, el descubrimiento del Nuevo Mundo por los españoles y la llegada a las Indias Orientales por parte de los portugueses enriquecería sobremanera el catálogo zoológico con la inclusión de nuevas especies $^{37}$, aunque las mismas tardaron algún tiempo en ser integradas en el marco zoológico general, constituyendo uno de los impulsos para ello la publicación de la obra de Juan Eusebio Nieremberg Historia naturae maxime peregrina (Amberes, 1635), deudora a su vez en gran medida de los trabajos realizados por Francisco Hernández en la América española durante el último tercio del siglo $\mathrm{XVI}^{38}$. Hasta entonces, la recepción de las nuevas especies fue muy lenta: en su Tesoro de la lengua castellana de $1610^{39}$ Sebastián de Covarrubias solamente nos habla del caimán, el papagayo, "ave índica conocida» (p. 1342), o el pavo, «gallo de las Indias» (p. 1350), pero no incluye, por ejemplo, el armadillo, que sí aparece ya en la obra de Gessner. Esta invisibilidad de la fauna indiana tendría sus consecuencias, ya que, precisamente, fueron las disparidades existentes entre los conocimientos heredados de la Antigüedad y las experiencias del Nuevo Mundo las que forzaron una reorganización de los modelos epistemológicos y

29. Sobre los presupuestos de la historia natural que nace a partir de mediados del Seiscientos, FOUCAULT, Michel, Las palabras y las cosas. Una arqueología de las ciencias humanas, Buenos Aires, Siglo XXI, 1968, pp. 128ss. La comparación entre Aldrovandi y Buffon, en pp. 47-48.

30. GESSNER, Conrad, Quadrupedes vivipares (Zurich, 1551), Quadrupedes ovipares (Zurich, 1554), Avium natura (Zurich, 1555) y Piscium \& aquatilium animantium natura (Zurich, 1558).

31. Belon, Pierre, De aquatilibus. París, Carolum Stephanum, 1553.

32. Rondelet, Guillaume, Histoire entière des poissons. Lyon, Mace Bonhome, 1558.

33. Salviani, Hipólito, Aquatilium Animalium Historia (Roma, 1554).

34. AldrovAnd, Ulises, Ornithologiae (Bolonia,1599-1603), De animalibus insectis (Bolonia, 1602), De piscibus (Bolonia, 1605), Quadrupedum omnium (Bolonia, 1621).

35. TOPSELL, Edward, The history of four-footed beasts and serpents (Londres, 1607).

36. JONSTON, Johannes, Historiae naturalis (Amsterdam, 1657).

37. Alvarez Pelaez, Raquel, La conquista de la naturaleza americana (Madrid, CSIC, 1993); ASUA, Miguel de, y FRENCH, Roger, New World of Animals. Early Modern europeans on the creatures of Iberian America, Aldershot, 2005.

38. VArey, S., Chabran, Rafael, y Weiner, D.W. (eds.), Searching for the secrets of nature. The life and works of Dr. Francisco Hernández. Stanford U.P., 2000.

39. Citamos por Covarrubias Horozco, Sebastián de, Tesoro de la lengua castellana o española, edición integral e ilustrada de Ignacio Arellano y Rafael Zafra, Universidad de Navarra, 2006. 
un abandono de los autores clásicos ${ }^{40}$...lo contrario, justamente, de lo practicado hasta entonces, ya que para muchos autores tan auténtico era lo leído como lo visto ${ }^{41}$.

La consolidación de estos intereses descriptivistas también ha sido abordada en el caso español, fundamentalmente por parte de los historiadores de la ciencia, comenzando, por supuesto, con la literatura relativa a las nuevas perspectivas que abrió a la zoología el descubrimiento de la fauna americana, tras las primeras visiones que se limitaban a trasponer los viejos bestiarios medievales ${ }^{42}$ (y, de hecho, durante mucho tiempo lo mítico y lo fabuloso siguieron teniendo cabida ${ }^{43}$, destacando al respecto las referencias de López Piñero ${ }^{44}$, y la obra de Raquel Alvarez Peláez ${ }^{45}$, a la que podríamos añadir los trabajos de José Pardo Tomás ${ }^{46}$, Antonio Barrera ${ }^{47}$, los análisis sobre Francisco Hernández debidos a Simon Varey ${ }^{48}$, y, más recientemente, la magnífica

40. Barrera-Osorio, A., Experiencing Nature. The Spanish American Empire and the Early Scientific Revolution, Texas U.P., 2006, p. 103.

41. «Cuando se hace la historia de un animal... es necesario recoger...todo lo que ha sido relatado por la naturaleza o por los hombres», FOUCAULT, Michel, op. cit., p.47.

42. Fischer, M.L., «Zoológicos en libertad: la tradición del bestiario en el Nuevo Mundo», Revista Canadiense de Estudios Hispánicos, 20-3, 463-476, 1996; Gomez TABANERA, José Manuel, «Sobre el bestiario fantástico del Medioevo europeo y su gravitación al Nuevo mundo avistado por Colón (1492)», Congreso de Historia del Descubrimiento 1492-1556, vol. 1, pp. 459-498, «Bestiario y paraíso en los viajes colombinos; el legado del folklore medieval europeo a la historiografía americanista», Actas del XI Congreso de la Asociación Internacional de Hispanistas. Encuentros y desencuentros de culturas: desde la Edad Media al siglo XVIII, vol. 3, 1994.

43. VOS, Paula de, «The rare, the singular and the extraordinary: Natural History and the collection of Curiosities in Spanish Empire», Bleichmar, D., VOS, P. de, Huffine, K., y SheEhan, K., Science in the Spanish and Portuguese Empires 1500-1800, Stanford U.P., 2007. Algunas aportaciones de interés en Stols, E., Thomas, W., y Verberckmoes, J., (eds.), Naturalia, Mirabilia et Monstrosa en los Imperios ibéricos. Leuven University Press, 2006.

44. Lopez PIÑERo, J.M., Ciencia y técnica en la sociedad española en los siglos XVI y XVII, Barcelona, Labor, 1979; El códice de Honorato Pomar: plantas y animales del Viejo Mundo y de América, Valencia, Ayuntamiento, 2000; Medicina e historia natural en la sociedad española de los siglos XVI y XVII, Universitat de Valencia, 2007.

45. La historia natural en los siglos XVI y XVII (Madrid, Akal, 1991), La conquista, «La historia natural en los tiempos del emperador Carlos V: la importancia de la conquista del Nuevo Mundo», Revista de Indias, 60, 218, 2000; «La descripción de las aves en la obra del madrileño Gonzalo Fernández de Oviedo», Asclepio, 48, 1, 1996; «La historia natural de los animales», GARCIA BALLESTER, Luis, Historia de la ciencia y de la técnica en la corona de Castilla, vol. 3 (siglos XVI y XVII), Valladolid, 2002.

46. Pardo Tomas, José, «La expedición de Francisco Hernández a México», Felipe II, la ciencia y la técnica, Madrid, 1999; El tesoro natural de América: colonialismo y ciencia en el siglo XVI. Oviedo, Monardes, Hernández, Madrid, Nivola, 2002; Un lugar para la ciencia: escenarios de práctica cientifica en la sociedad hispana del siglo XVI, Fundación Canaria Orotava, 2006.

47. BArrera-Osorio, A. Experiencing Nature; «Knowledge and Empiricism in the Sixteenth Century Spanish Atlantic World», Science in the Spanish.

48. VAREY, S., (ed.), The mexican treasury: the writings of Dr. Francisco Hernández, Stanford U.P., 2000; VAREY, S., CHABRAN, R., y WEINER, D.W., (eds.), Searching for the secrets of nature. The life and works of Dr. Francisco Hernández. Stanford U.P., 2000. 
visión de conjunto de Miguel de Asúa y Roger French ${ }^{49}$. La revista Asclepio presenta asimismo algunas contribuciones interesantes ${ }^{50}$ centradas fundamentalmente en un siglo XVIII en el cual la política zoológica de los Borbones tendría su máxima expresión en la fundación del Real Gabinete de Historia Natural ${ }^{51}$, cuya prueba de fuego sería el análisis de los fósiles del megaterio, magistralmente descrito por Juan Pimentel Igea $^{52}$.

Estudiar animales implica, ante todo, clasificarlos ${ }^{53}, \mathrm{y}$, de hecho, desde la época aristotélica, el conocimiento ha venido acompañado por la parcelación del saber: ordenar, clasificar y sistematizar es el primer paso para el estudio de las cosas. Y las clasificaciones nunca son eternas ni inmutables, antes al contrario, dependen de los valores culturales existentes en una sociedad ${ }^{54}$. Es por ello que durante mucho tiempo la clasificación de los animales siguió unos criterios totalmente distintos a los de nuestros días: se empleaban parámetros habitacionales, según los cuales lo que importaba era el lugar en el que residían los animales (se hablaba así de animales terrestres, acuáticos y aéreos, y es por ello por lo que las ballenas, los delfines, las tortugas, y los cocodrilos, solían ser incluidos junto a los peces), y no morfológicos, que solamente triunfan a partir del siglo XVIII con la obra de Linneo.

Esta clasificación habitacional la podemos encontrar en numerosos autores. Bernardino de Sahagún, por ejemplo, en su Historia general de las cosas de Nueva España, nos habla de animales (por las descripciones se ve que eran terrestres y en general cuadrúpedos), aves, animales de agua (comprende peces, algunos crustáceos y quelonios, pero también el armadillo y la iguana seguramente porque eran comestibles y porque no sabía bien donde ponerlos), animales de agua no comestibles (caimanes, culebras de agua, y el ahuitzotl, quizás una nutria, o simplemente un animal fantásti-

49. ASUA, Miguel de, y FRENCH, Roger, A new world of animals. Early modern europeans on the creatures of Iberian America, Aldershot, 2005.

50. Por citar algunas de ellas, GALERA, Andrés, y FRIAS, Marcelo, «Félix de Azara y Georges Lucien Leclerc: dos formas de iluminar la naturaleza americana» (48, 1, 1996), MAZO PEREZ, A.M., «El oso hormiguero de su Majestad» $(58,1,2006)$, PEDRO, Antonio E. De, «El zoo de papel: un análisis de la imagen científica sobre los animales en el siglo XVIII» (44, 1, 1992), PELAYO, Francisco, y FrIAS, Marcelo, «Antonio José Cavanilles y la Historia Natural francesa» (47, 1, 1995), ZARZOSO, M., «Medicina para animales en la Cataluña del siglo XVIII» $(59,1,2007)$.

51. Calatayud Alonso, M.A., «El Real Gabinete de Historia Natural de Madrid», Selles, M., (comp.), Carlos III y la ciencia de la Ilustración, Madrid, Alianza, 1988. PIMENTEL IGEA, Juan «La naturaleza representada. El Gabinete de Maravillas de Franco Dávila», Testigos del mundo. Ciencia, literatura y viajes en la Ilustración, Madrid, Marcial Pons, 2003. VillenA, M., et al., El gabinete perdido. Pedro Franco Dávila y la Historia Natural del siglo de las Luces, 2 vols., Madrid, CSIC, 2008. Para un contexto general, BlEICHMAR, D., «A visible and useful empire: Visual Culture and Colonial Natural History in the Eighteenth Century Spanish World», Science in the Spanish.

52. Pimentel IGEA, Juan, El rinoceronte y el megaterio, Madrid, Abada, 2010.

53. Algunas reflexiones al respecto en VIEJO MonTESINOS, José Luis, «El hombre como animal: el antropocentrismo en la zoología», Asclepio, 48, 2, 1996.

54. Pastoureau, Michel, El oso. Historia de un rey destronado, Barcelona, Paidós, 2008, pp. 23-24. 
co), serpientes y otros animales de tierra (serpientes e insectos) $)^{55}$. Un esquema parecido sigue Gonzalo Fernández de Oviedo en su Primera parte de la historia general y natural de las Indias occidentales (1535): animales terrestres, animales acuáticos, aves e insectos ${ }^{56}$. Hasta la publicación del Systema naturae (Leyden, 1735, con numerosas ediciones posteriores) de Linneo no se inauguraría la clasificación morfológica del mundo animal, distinguiendo el naturalista sueco al respecto en su edición de 1758 (considerada el punto de partida de la moderna nomenclatura zoológica) entre los mammalia (mamíferos), denominados en las primeras ediciones quadrupedia, las aves, los amphibia (donde incluye también los reptiles), los pisces, los insecta (los artrópodos) y los vermes (los restantes invertebrados). Clasificación que, todo hay que decirlo, no fue aceptada automáticamente: el conde de Buffon en su magna Historia natural general y particular (1746-1788), todavía nos sigue hablando de los cuadrúpedos.

Y estudiarlos también supone plasmarlos visualmente, no pudiéndose olvidar la obra del historiador del arte Barbero Richart, Iconografia animal. La representación animal en libros europeos de Historia Natural de los siglos XVI y XVII (Universidad de Castilla la Mancha, 1999), que aborda el fascinante mundo de las representaciones iconográficas incluidas en la rica literatura zoológica de la Modernidad. Pero no era tan fácil conseguir imágenes de animales. Los libros de historia natural de los siglos XVI y XVII aún heredan toda una tradición mitológica y fantasiosa de los bestiarios, encontrándose descripciones de animales con los rasgos y comportamientos exagerados o que hoy se consideran irreales, en tanto las representaciones de siglos posteriores son más realistas. En los libros de viajes las ilustraciones de animales estaban muy influidas por el grado de fantasía que pudiera tener el relato, y algunos de ellos están poblados de descripciones de seres monstruosos y de sus respectivas imágenes. La escasez de modelos animales, especialmente cuando éstos eran extraños, obligó a muchos ilustradores a inspirarse directamente en los textos, y en la descripción de un animal nuevo y desconocido se acudía mucho al uso de la comparación, método que generaba errores: en la época medieval era muy habitual representar al elefante como a un cerdo con trompas. La observación directa del animal casi nunca era posible, y, ante la escasez de imágenes, era muy frecuente que se copiaran una y otra vez aquellas ilustraciones de animales poco habituales (el rinoceronte es un ejemplo emblemático al respecto $)^{57}$, y a veces es el comportamiento o cualidades del animal lo que sirve de base a su descripción, como la salamandra apagando el fuego o cruzando las llamas ${ }^{58}$. La razón de fondo de todo ello era el hecho de que no era frecuente ver determinados animales, y el ejemplo del rinoceronte es, una vez más, muy sintomático: el rinoceronte de Manuel I de Portugal, Ganda, fue el primero que llegó a Europa desde la época romana, siendo seguido por el de Felipe II, Bada. Y hasta mediados del siglo XVIII no

55. Alvarez Pelaez, Raquel, La conquista, pp. 91-92.

56. PARdo TOMAS, José, El tesoro.

57. Pimentel, Juan, El rinoceronte, pp. 94ss.

58. BARBERo Richart, Manuel, Iconografía animal. La representación animal en libros europeos de Historia Natural de los siglos XVI y XVII, 2 vols., Cuenca, UCLM, 1999. 
arribaría el tercero, Clara, aunque ésta sí realizaría un largo periplo por todo el continente. Ello no impediría, no obstante, que podamos encontrar a magníficos artistas especializados, precisamente, en pintar animales, como Jean Baptiste Oudry o George Stubbs, especialización que no pareció existir en el caso hispánico, aunque podamos reseñar las hermosas láminas presentes en la obra de Antonio Parra, Descripción de diferentes piezas de historia natural las más del ramo maritimo (La Habana, 1787).

Hasta el siglo XVIII no se organizaron expediciones científicas con la misión de recopilar, describir y dibujar sistemáticamente todos los especímenes, animales o plantas, que se encontraran ${ }^{59}$. Había que conformarse, hasta entonces, con dibujar a los animales que se encontraran en el continente europeo, bien naturales, bien exóticos. Estos últimos podían localizarse, en mayor o menor cantidad, en los parques zoológicos o ménageries ${ }^{60}$, que los monarcas europeos, como una forma de demostrar su poder y su dominio universal, mantenían a su costa. Ejemplos muy estudiados son los de la Italia renacentista, Manuel I de Portugal y Felipe II de España, pero el gran modelo fue la ménagerie que Luis XIV mantuviera en Versalles, que prolongaría su existencia, si bien con altibajos, hasta los años de la Revolución. Carlos III, por su parte, relanzaría la colección animalística de la monarquía española en los últimos años del siglo XVIII, todo ello muy bien estudiado por Carlos Gómez Centurión ${ }^{61}$, procediéndose asimismo a la fundación en 1776 del Real Gabinete de Historia Natural, cuyos contenidos podemos apreciar a través de la obra de Juan Bautista Bru Colección de láminas que representan los animales y monstruos del Real Gabinete de Historia Natural (1784).

Más que su comportamiento o su conducta, lo que interesó en un primer momento fue el estudio de los caracteres morfológicos de las distintas especies animales, y esta obsesión anatómica la podemos encontrar por doquier: Buffon le dedica bastante espacio a los órganos anatómicos y a las mediciones cuantitativas de las distintas partes de cada animal. Y lo mismo hará el gran naturalista español de la Ilustración, Félix de Azara, en sus Apuntamientos para la historia natural de los cuadrúpedos del Paraguay y del Río de la Plata (Madrid, 1802), y Apuntamientos para la historia natural de los pájaros del Paraguay y del Río de la Plata (Madrid, 1802-1805). Labor de disección y deconstrucción que, por otra parte, sería muy útil cuando a finales del

59. Un ejemplo entre muchos otros GOnZALEZ ClaVERAn, Virginia, La expedición científica de Malaspina en Nueva España 1789-1794, México, 1988. También, MALdONADo Polo, José Luis, Las huellas de la razón. La expedición cientifica de Centroamérica (1795-1803), Madrid, CSIC, 2001.

60. BARATAY, Eric, y HARDOUIN-FUGIER, Elizabeth, Zoo: a history of zoological gardens in the west, Nueva York, 2004. Una obra de divulgación, pero muy bien hecha, BELOZERSKAYA, Marina, La jirafa de los Médici. Y otros animales exóticos y el poder, Barcelona, Gedisa, 2006.

61. Véase las obras de Gomez CENTURION, Carlos, «Exóticos pero útiles: los camellos reales de Aranjuez durante el siglo XVIII», Cuadernos dieciochistas, 9, 2008; «Treasures fit for a king. King Charles III of Spain's Indian Elephants», Journal of the History of Collections, 2009; «Exóticos y feroces. La ménagerie real del Buen Retiro durante el siglo XVIII», Goya. Revista de Arte, 326, 2009; "Curiosidades vivas. Los animales de América en la Ménagerie real durante el siglo XVIII», Anuario de Estudios Americanos, 66, 2, 2009. También, Descripción del elefante, de su alimento, costumbres, enemigos e instintos, Madrid, Imprenta de Andrés Ramírez, 1773. 
siglo XVIII se descubrieron los primeros fósiles, destacando el esqueleto que apareciera en el Río de la Plata en 1787 de lo que fuera descrito, en un primer momento, como un cuadrúpedo muy corpulento y raro $^{62}$, y que sería reconstruido en el Gabinete de Historia Natural de Madrid, siendo bautizado por el naturalista francés Cuvier con el nombre de megaterio ${ }^{63}$.

En las últimas décadas del siglo XVIII el interés por los aspectos descriptivos del mundo animal parece remontar en España, como revela la producción propia (Ignacio de Asso, «Introducción a la ictiología oriental de España», Anales de Historia Natural, 10, 1801; las obras de Azara ya citadas, Antonio José Cavanilles, «Historia natural de las palomas domésticas de España especialmente de Valencia», Anales de Historia Natural, 2, 1799; José Andrés Cornide, Ensayo de una historia de los peces y otras producciones marinas de la costa de Galicia, Madrid, 1788; Gaspar Casal, Historia natural y médica de el principado de Asturias, Madrid, 1762; Simón Clemente y Rubio, Historia natural de Granada, manuscrito, 1805; Gaspar Torrubia, Aparato para la historia natural española, Madrid, 1754; José Viera y Clavijo, Diccionario de historia natural de las Islas Canarias, no publicado hasta el siglo XIX), las traducciones de obras francesas (siendo de destacar la realizada de la obra de Buffon por José Clavijo y Fajardo entre 1786 y 1805, precedida de la versión española del Espectáculo de la naturaleza del abate Pluche, publicada entre 1753 y 1755 por Esteban Terreros y Pando), o el surgimiento de publicaciones tales los Anales de Historia Natural/Anales de Ciencias Naturales (1799-1804) o Variedades de ciencia, literatura y artes, en la que autores como Juan Blasco Negrillo pudieron tratar temas como «Noticia de la loba marina que hay en el Buen Retiro» (VI, 1805), o «De las perlas» (VI, 1805). La existencia de un público interesado debe encontrarse detrás de esta floración bibliográfica, lo que movería a un autor anónimo a escribir en El Correo de Madrid (VII, 1790, 353) un artículo sobre las ciencias naturales y sobre la belleza y la utilidad de su estudio.

\section{LA VISIÓN AFECTIVA}

Ya desde la Antigüedad la consideración que han merecido los animales ha suscitado opiniones muy distintas, destacando al respecto, en el plano positivo, las valoraciones de Plutarco, y la escolástica medieval continuó con esta divergencia de opiniones. Por un lado, hay quienes los oponen al hombre, como criaturas sumisas e imperfectas que son, y esta corriente insiste en su dominio absoluto sobre los animales (lo que llamamos visión utilitaria): tal como bien subrayan Karl Enenkel y Paul Smith, la única razón de éstos es la de servir al ser humano, proporcionándole comida, ropa, medios de transporte, medicinas, y entretenimiento ${ }^{64}$. Esta corriente lleva a reprimir con severidad todo comportamiento que asemeje al hombre y los animales, como las

62. GARRIGA, Joseph, Descripción del esqueleto de un quadrúpedo muy corpulento y raro que se conserva en el Real Gabinete de Historia Natural de Madrid, Madrid, Joaquín Ibarra, 1796.

63. PIMENTEL, Juan, El rinoceronte.

64. Enenkel, K.A., y SMith, P.J., «Introduction», Early Moderrn Zoology, p. 2. 
prohibiciones de disfrazarse de él, imitar su comportamiento, o tenerles demasiado afecto, y, muy posiblemente, sea la caza el ejemplo más evidente de dominación del hombre sobre el mundo animal. Tal como expresara con meridiana claridad Alonso Martínez de Espinar en su Arte de ballestería y montería de 1644, y reeditado en 1761, caza no es «otra cosa que seguir en el campo las aves y fieras que están libres para reducirlas a nuestro dominio y servicio» (lib. 1, cap. 1). Esta actividad siempre ha tenido muchas funcionalidades: en la época medieval se podía practicar como pasatiempo, necesidad, o ritual social. La caza era una actividad deportiva, que permitía mantenerse en forma, y constituía un magnífico entrenamiento para el combate, por lo que no es de extrañar que fuera el divertimento por antonomasia de la aristocracia ${ }^{65}$. Era una actividad de prestigio, ya que no solamente entrañaba el enfrentamiento directo contra una bestia feroz, sino que necesitaba grandes medios económicos para sufragar el costoso aparato constituido por jaurías, halcones, oteadores y monturas. Era una actividad muy codificada y reglamentada, como consecuencia del fuerte espíritu de emulación existente entre los cazadores. Y era una actividad dotada de un profundo contenido moral, ya que aseguraba la salud y proporcionaba un placer que no es pecaminoso, constituyendo además un remedio contra la ociosidad, la madre de todos los vicios. La acción que requiere la caza neutraliza los malos pensamientos y es un antídoto contra el mal ${ }^{66}$. Y esta práctica cinegética dará origen a una abundante literatura, de la que podríamos destacar obras como El cazador instruido de Juan Manuel de Arellano (Madrid, 1745), Libro de la montería de Gonzalo Argote de Molina (Sevilla, 1582), los Diálogos de la montería de Barahona de Soto (de finales del XVI, aunque no publicada hasta 1890), la Silva venatoria de Agustín Calvo Pinto (Madrid, 1754), el Arte de ballestería y montería de Alonso Martínez de Espinar (Madrid, 1644), o el poema La Diana o el arte de la caza (Madrid, 1765) de Nicolás Fernández de Moratín, aunque hace muchos años que toda esta producción ya ha sido recogida y sistematizada ${ }^{67}$.

La segunda corriente, que muestra una opinión más considerada hacia los animales, es a la vez aristotélica y paulina. Ya el primero estableció una especie de comunidad entre todos los seres vivos, idea presente en De anima. Por otro lado, Pablo, en Rom. 8, 21, decía «la creación entera espera anhelante ser liberada de la servidumbre de la corrupción, para participar en la libertad de la gloria de los hijos de Dios». Ello hizo que muchos se interrogaran sobre si Jesús vino a salvar también a los animales, y

65. «Caza real propio ejercicio de príncipes que por lo que tiene de belicoso templan con él a la paz el ardor de sus reales y heroicos corazones acostumbrados en la guerra a domar diferentes naciones y primera que los tiempos del ocio se gastasen en acción de tanta utilidad y estorbo de tantos vicios» (MARTINEZ DE EspinAR, Alonso, Arte de ballestería y montería, Madrid, 1644, lib. 2, cap. 2).

66. SMETS, Ann, «Medieval Hunting», RESL, Brigitte (ed.), A cultural history of animals in the Medieval Age, Oxford, Berg Publishers, 2007.

67. Fradejas Rueda, J.M., Textos clásicos de cetrería, montería y caza, Madrid, Mapfre, 1999; TERRON, M., El conocimiento animalístico de la caza mayor en los clásicos de la montería hispana, Trujillo, 1992. El contexto ideológico, en CARO LOPEZ, J., «La caza en el siglo XVIII: sociedad de clase, mentalidad reglamentista», Hispania, 224, 2006. 
en la escolástica se planteaba si iban al cielo, si podían trabajar los domingos o si tenían responsabilidad moral. Si la tradición clásica despreciaba a los animales, el cristianismo los dota de un alma más o menos racional y se pregunta si son responsables de sus actos, lo que llevó, en un caso extremo, a los juicios contra animales, muy frecuentes en los últimos siglos medievales en Francia, siendo los cerdos las víctimas propiciatorias más frecuentes ${ }^{68}$, en tanto que en España los procesos contra la langosta fueron moneda de cambio muy habitual a lo largo de los siglos XVI y XVII ${ }^{69}$, persistiendo en el Siglo de las Luces una florida literatura de rogativas y conjuros destinados a ahuyentar esta plaga.

Este es el panorama existente cuando un monje benedictino, Francisco de Blasco Lanuza, escribe Patrocinio de ángeles y combate de demonios (San Juan de la Peña, 1652), obra ya estudiada por María Tausiet y por nosotros $\operatorname{mismos}^{70}$, y que constituye un buen ejemplo de cómo, cuado uno se adentra en la la historia de los animales, no se imagina hasta qué punto son inabarcables las fuentes a nuestra disposición, por cuanto en el texto más insospechado podemos encontrar referencias de interés. Pero es bien cierto que el historiador, en la mayor parte de las ocasiones, solamente encuentra lo que busca: los análisis anteriores de nuestro buen monje se habían preocupado especialmente por su visión escatológica, sea por el gran desarrollo que en la misma adquiere el mundo angelical, sea por el análisis de su contrapunto demoníaco (y de todos sus perversos colaboradores), sea por la conexión del benedictino con las posesiones colectivas que conociera el Pirineo aragonés en la década de 1630. Pero, de una forma casi inadvertida, el autor nos desarrolla toda una visión del mundo animal, por cuanto en la primera parte del libro primero, dedica sendos capítulos al sumo cuidado que Dios tiene de socorrer las necesidades de las aves y peces (c. II) y a las armas y astucias que da a los animales para defender sus vidas (c. III).

Correspondiendo a la segunda tradición de la escolástica, nuestro monje llega incluso a plantearse si los animales gozan de la protección del Angel Custodio. La respuesta no puede menos que ser afirmativa, no tanto por ellos mismos, cuanto por el amor que Dios siente hacia el hombre, de tal modo que para asegurar su vida provee de ángeles custodios a sus servidores los animales. Se remite a la autoridad de Santo Tomás de Aquino, que afirmó, basándose a su vez en San Agustín, que toda criatura corporal es administrada por los ángeles: Omnia corpora reguntur per spiritum vita rationalem (todos los cuerpos son regidos por criatura espiritual) y Unaquaque res visibilis, in hoc mundo, habes Angelicam potestatem sibi prapositam (cualquier cosa visible del mundo tiene su Angel que le defiende), así como en San Gregorio Magno,

68. Pastoureau, Michel, Una historia simbólica de la Edad Media Occidental, Buenos Aires, Katz Editores, 2006, pp. 27-30.

69. SANZ DAROCA, Cosme, Las respuestas religiosas ante las plagas del campo en la España del siglo XVII, Madrid, UNED, 2008, Tesis doctoral inédita.

70. Morgado Garcia, Arturo, «Angeles y demonios en la España del Barroco», Chronica Nova, 27, 2000, TAUSiet CARLES, María, «La batalla del bien y del mal: Patrocinio de ángeles y combate de demonios», Hispania sacra, 123, 2009. 
para el cual los distintos órdenes de ángeles son asignados a diversos géneros de criaturas, lo que incluye implícitamente a los animales (p. 287).

No obstante, para salvar las apariencias, Lanuza acude a una pirueta dialéctica, en lo que sigue a San Gregorio: si los seres humanos tienen un ángel individual, los animales gozan de un ángel custodio para cada especie, ya que, al fin y al cabo, hay que jerarquizar, algo que siempre fue muy querido para la escolástica. Del mismo modo, los ángeles que cuidan de los animales no pertenecen a la misma jerarquía que los que velan por nosotros. Durante la Edad Moderna la autoridad indiscutible en angeología fue el jesuita español Francisco Suárez (1548-1617), y a su sapiencia se remite Lanuza cuando afirma que los ángeles de inferior categoría se ocupan de las criaturas insensibles, como plantas o árboles, los de medio grado, de las distintas especies animales, y, finalmente, los de la jerarquía suprema son los encargados de velar por los hombres. Si los animales gozan de la protección angelical, parecería claro que el ser humano tiene ciertas obligaciones hacia ellos, aunque Lanuza no se atreve a dar este paso.

Tampoco era, ciertamente, el objeto de su libro, pero esta consideración hacia el mundo animal dista sobremanera de otros coetáneos suyos, si bien las posturas nunca fueron unánimes: en la España del siglo XVI oscilaban entre el automatismo de Gómez Pereira, precursor de la visión cartesiana al respecto (que era absolutamente mecanicista), plasmada en su Antoniana Margarita (Medina del Campo, 1554); hasta sus detractores, que les reconocían la capacidad de sentimiento, figurando entre ellos Francisco de Sosa en su «Endecálogo contra Antoniana Margarita, en el cual se tratan muchas y muy delicadas razones, y autoridades con que se prueba, que los brutos sienten y por sí se mueven» (Medina del Campo, 1556). El mismo Feijoo se ocuparía de estas cuestiones en su «Discurso sobre el alma de los brutos» (Teatro crítico universal, tomo III, discurso IX, 1729), que sería criticado por Miguel Pereira de Castro en su Propugnación de la racionalidad de los brutos (Lisboa, 1753) ${ }^{71}$.

Ello contrasta con el tratamiento que se le da a los animales domésticos, especialmente en Inglaterra, a partir del siglo XVII ${ }^{72}$, si bien sabemos muy poco acerca de la presencia de éstos o de las mascotas en el mundo hispánico ${ }^{73}$, de la consideración que merecían hacia sus dueños, o de las especies más recurrentes. La producción dieciochesca es muy reducida al respecto, y se centra especialmente en las aves de jaula, como revelan las obras de José Patricio Moraleja y Navarro, Tratado breve útil y curioso de los más especiales pájaros de cántico (Madrid, 1740), Francisco Surias, Instrucción y modo fácil e inteligible para coger y conservar el rey de las aves de cántico llamado el ruiseñor (Madrid, 1796), o Juan Bautista Zamarro, Conocimiento de las catorce aves menores de jaula (Madrid, 1775). Y llama la atención, especialmente, la ausencia de una literatura específicamente dedicada al animal de compañía por exce-

71. Rodríguez PARdo, José Manuel, El alma de los brutos en el entorno del padre Feijoo, Oviedo, Pentalfa Ediciones, 2008.

72. ThOMAS, Keith, Man and the natural world. Changing attitudes in England 1500-1800, Londres, 1983).

73. Perez De Tudela, A., y Jordan, A., «Renaissance Menageries, Exotic Animals and Pets at the Habsburg Courts in Iberia and Central Europe», ENENKEL, K.A.E., y SMITH, P.J., Early Modern Zoology. 
lencia, al menos en la actualidad, a saber, el perro, lo que contrasta con la existencia de numerosas obras que polemizan sobre la conveniencia de tener o no gatos en casa so pretexto de eliminar los ratones, como las de Mariano Madramany y Calatayud, Oración en que se persuade que es menor mal sufrir ratones que tener gatos en nuestras casas (Madrid, 1779), Marcos Antonio de Orellana, Disertación persuadiendo que es menor mal sufrir ratones que tener gatos (Valencia, 1779), o Miguel Serrano Belezar, Declamaciones y sentimientos que hicieron los gatos de Madrid (Madrid, 1779).

Sin embargo, en los años centrales del siglo XVIII algo debía ir moviéndose en España, y un buen observatorio para estas cuestiones lo tenemos, como para otras tantas cosas, en la obra de Feijóo $^{74}$, que recogerá la conocida anécdota de la paloma herida que fuera cariñosamente recogida por (el futuro) Fernando VII y Bárbara de Braganza $^{75}$. Lo cierto es que resulta muy sintomático que alguien se tomara, a fines de la centuria, la molestia de traducir las «Reflexiones de Pope sobre la crueldad con los animales» (Misceláneas instructiva, curiosa y agradable, I, 1796, num. 3), lo que revela la existencia de una opinión ya sensibilizada con estas cuestiones. Si bien tener animales de compañía no implica necesariamente sentir afecto por ellos: es muy significativo que Leandro Fernández de Moratín, en una carta escrita en 1817, definiese a su gato negro y a su galápago como alimañas $^{76}$.

74. FEIJOO, Benito Jerónimo de, Cartas eruditas y curiosas, tomo tercero, 1750, carta 27, «Si es racional el afecto de compasión respecto de los irracionales».

75. FeIJOO, Benito Jerónimo de, Ibidem. Damos las gracias al profesor Carlos Gómez-Centurión por haber llamado nuestra atención sobre este punto.

76. Los Moratines. Obras completas, tomo 2, Madrid, Cátedra, 2008, edición de Jesús Pérez Magallón, carta 169 , p. 1354. 